Journal of Computer Science 5 (2): 140-145, 2009

ISSN 1549-3636

(C) 2009 Science Publications

\title{
Comparative Studies on the Performance of Low Power Transmitters for Wireless Sensor Nodes
}

\author{
${ }^{1}$ T. Sasilatha and ${ }^{2}$ J. Raja \\ ${ }^{1}$ Anna University, Chennai-600 025, India \\ ${ }^{2}$ Department of Information Technology, Sri Sivasubramaniya Nadar College of Engineering, \\ Kalavakkam-603 110, Tamil Nadu, India
}

\begin{abstract}
Problem statement: Power consumption was one of the most challenging aspects to design low power wireless sensor nodes. The objectives of the study were to (i) Design low voltage, low power transmitters for wireless sensor nodes and (ii) Compare and analyze the performance of the transmitters. Approach: The transmitters employed direct digital modulation scheme to reduce the power consumption of the sensor nodes. Emphasis was placed on observing device reliability constraints at low power to maximize the life time of the wireless sensor nodes. Results: The Amplitude Shift Keying (ASK) transmitter consumed a power of $400.104 \mu \mathrm{w}$ from the $1.2 \mathrm{~V}$ supply. The Frequency Shift Keying (FSK) and Phase Shift Keying (PSK) transmitters consumed $520 \mu \mathrm{w}$ and $5.2 \mathrm{mw}$ respectively at $2.4 \mathrm{GHz}$. The transmitters suitable for low voltage, low power wireless sensor nodes were designed and implemented in $120 \mathrm{~nm}$ CMOS technology Conclusion: The performances of the ASK, FSK and PSK transmitters were analyzed and were compared with the previously reported low power approaches operated in similar frequency ranges.
\end{abstract}

Key words: Wireless micro sensor nodes, ASK, FSK, PSK, modulator, power amplifier, frequency synthesizer

\section{INTRODUCTION}

The emerging field of wireless sensor networks offers a rich, multi-disciplinary area of research, in which a variety of tools and concepts can be employed to address a diverse set of applications. The embedded nature of the applications and large number of nodes makes changing batteries impractical ${ }^{[1]}$. One of the major challenges in constructing such networks is to maintain long network lifetime. To achieve this goal low power research is concentrated in the wireless sensor networks. WSN consists of many distributed and disposable sensor nodes that require a highly integrated, low cost single chip transceiver with high energy efficiency. To consume less power it should work at a low duty cycle. The energy consumed by a transmitter is due to two sources. One part is due to RF signal generation which is mainly due to modulation and the other part is due to the electronic components needed for frequency synthesis, frequency conversions, power amplifiers, filters and so on. These costs are basically constant $^{[2]}$.

The focus of this research is the realization of a high performance, integrated transmitter in CMOS.
Hence the performance of the low power transmitters are analyzed and the results are discussed based upon the results reported in the literature.

Although the modulators using SOICMOS process has demonstrated excellent performances, the standard bulk CMOS process is still attractive for low cost applications. There were some standard bulk CMOS modulators reported in the literature ${ }^{[3-7]}$. In this study, we designed low power CMOS ASK, FSK and PSK transmitters at $2.4 \mathrm{GHz}$ and the performances are compared with other existing transmitters operating in the similar frequency ranges. Several factors must be considered carefully when determining the modulation scheme of WSN. The most important factors are power efficiency, signal quality and the simplicity of the modulation and demodulation circuits used in the design. Normally BFSK modulation scheme simplifies the modulation and the detection circuit complexity. Depending upon the applications, the modulators are selected and used. The transmitters presented in this study have better power performance than the previous transmitters reported in the literature.

Corresponding Author: T. Sasilatha, Anna University, Chennai-600 025, India 
Architecture of low power transmitters: Directdigital modulation can dramatically reduce size, weight and power consumption of the transmitter, by eliminating the IF circuit and the up converter circuits used in heterodyne systems. Hence they are very much suitable for wireless sensor network applications. Figure 1 shows the transceiver in wireless sensor nodes. Simplified block diagram of a direct digital Transmitter is shown in the Fig. 2.

Here depending upon the applications of the wireless sensor networks either ASK or FSK or PSK modulator must be selected.

PLL based frequency synthesizer: The role of frequency synthesizer is to provide reference frequency for frequency translation. Phase noise and spurious tones are the two key parameters to measure the quality of a frequency synthesizer.

A typical PLL based frequency synthesizer ${ }^{[8]}$ is shown in Fig. 3. The synthesizer is capable of generating a large number of highly accurate output frequencies. A power hungry circuit is the voltage controlled oscillator. Though there are a number of VCO categories are available, because of the need for

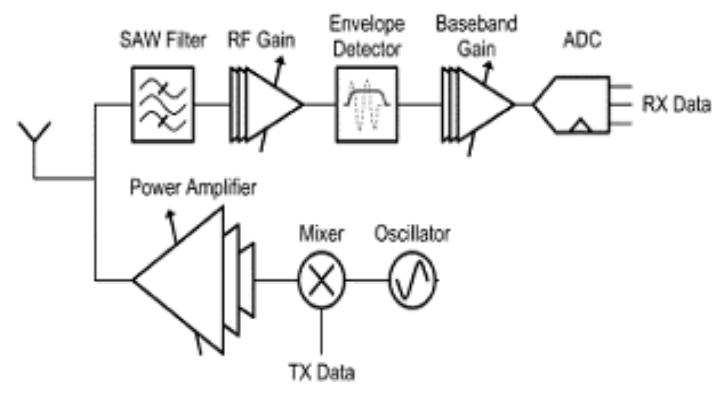

Fig. 1: Transceiver in wireless sensor nodes

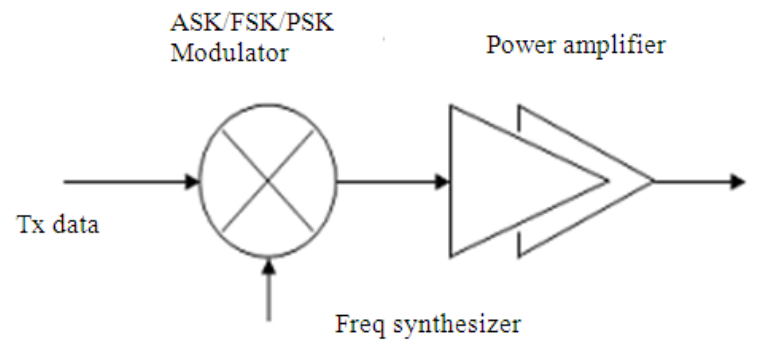

Fig. 2: Direct digital transmitter integrability, ring oscillator is very desirable in VLSI environments ${ }^{[9]}$. This configuration consumes less power of $0.322 \mu \mathrm{w}$ when compared to other circuits.

ASK modulator: As evidenced by (2), one way to increase the energy of communication is to reduce the transmit $T_{O N}$-time of the radio. From ${ }^{[10,11]}$, we see that the startup transient plays an important role in choosing a low power modulation scheme. Therefore ASK/FSK/PSK modulators are chosen and efforts are taken to reduce the power dissipation at circuit level. Also, the performance of these modulators are compared and the best modulator is selected depending upon the wireless sensor networks applications.

Figure 4 shows the circuit of an ASK modulator ${ }^{[12]}$. The corresponding output is shown in Fig. 5.

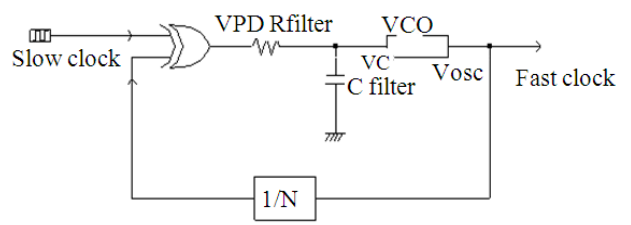

Fig. 3: Schematic of PLL based frequency synthesizer

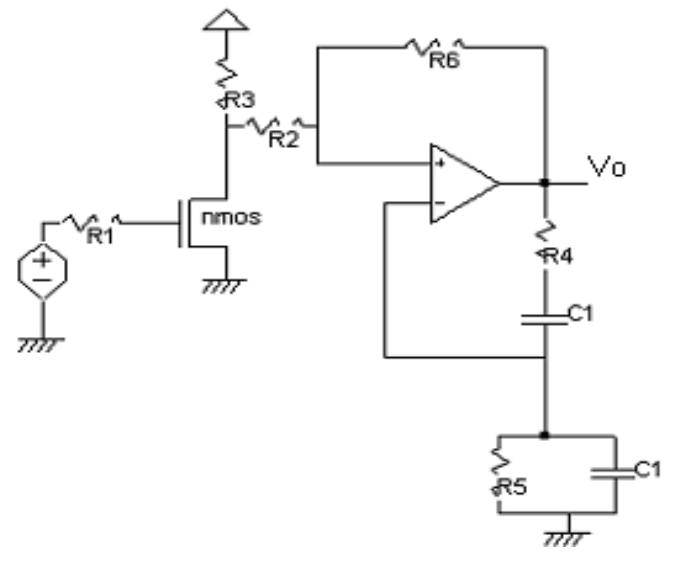

Fig. 4: ASK modulator

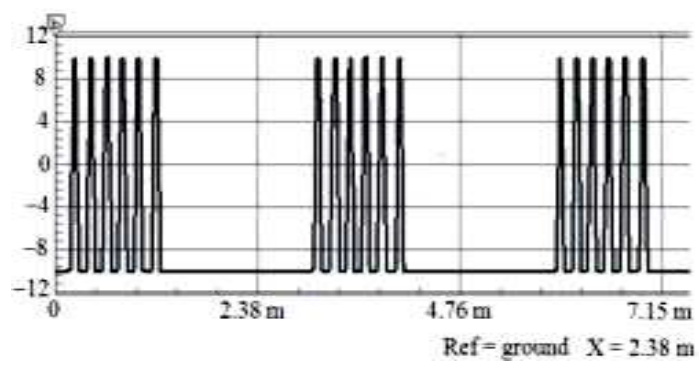

Fig. 5: Output of ASK modulator 


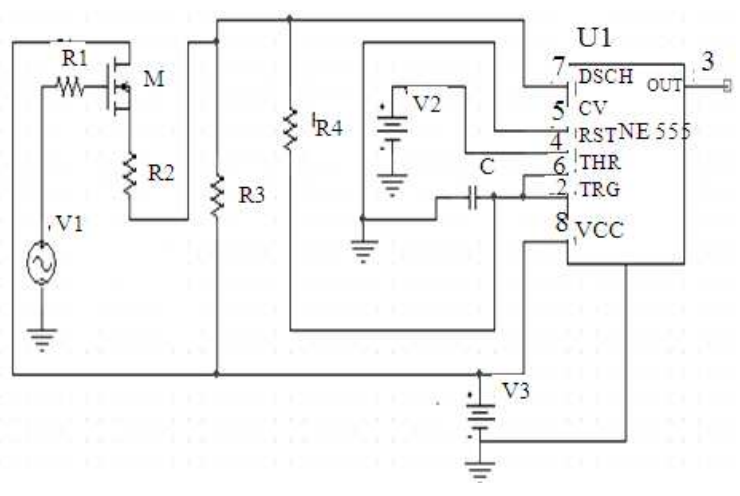

Fig. 6: FSK modulator

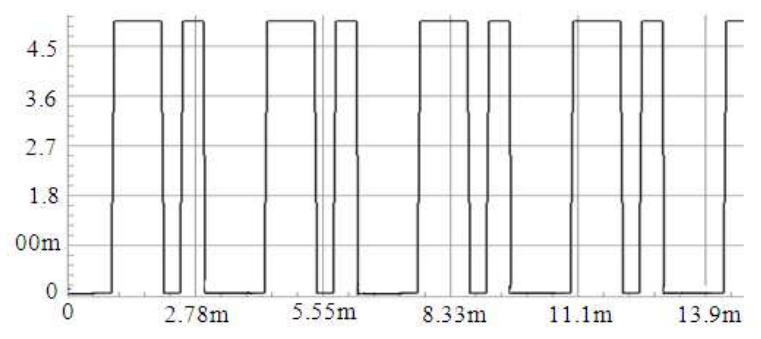

Fig. 7: Output of FSK modulator

In this modulator, the wein bridge oscillator produces oscillation and the NMOS transistor acts as a switch. At $2.4 \mathrm{GHz}$, the modulator consumes a power of 200.104 $\mu \mathrm{w}$.

FSK modulator: Though the modulation schemes such as QAM and MSK are popular in modern communications and have different filtering requirements and characteristics, FSK modulators are generally suitable for low power sensor networks. Figure 6 shows the circuit of a FSK modulator. The output of the modulator has two frequencies. One corresponds to data 1 and the other corresponds to data 0, as shown in Fig. 7.

At $2.4 \mathrm{GHz}$, the modulator consumes a power of $320 \mu \mathrm{w}$. The ON or OFF condition of the MOS transistor will depend upon the input signal. When the input signal is at logic 1 the output frequency can be found out from the equation,

$\mathrm{f}_{\text {mark }}=1.45 /\left(\mathrm{C}\left(\mathrm{R}_{3}+2 \mathrm{R}_{4}\right)\right)$

When the input signal is logic 0 , transistor is turned $\mathrm{ON}$. This reduces the charging time of capacitor $\mathrm{C}$ and increases the output frequency.

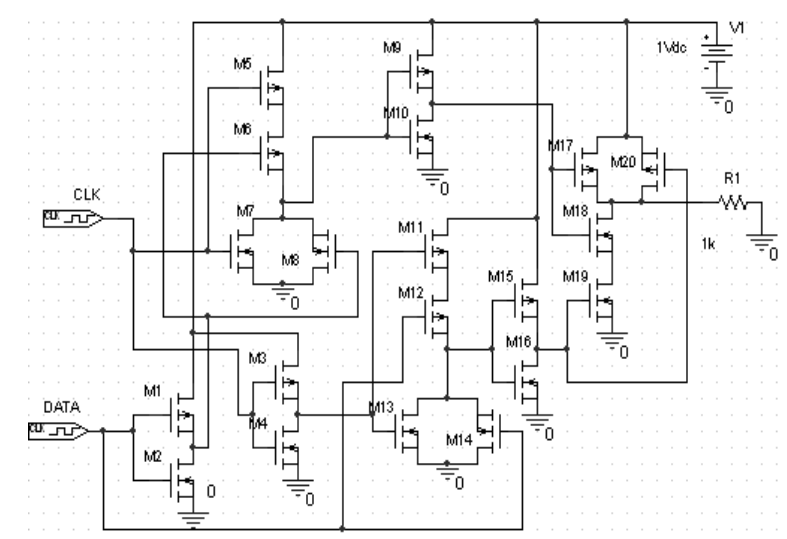

Fig. 8: PSK modulator

The output frequency corresponding to logic 0 can be described by,

$\mathrm{f}_{\text {space }}=1.45 /\left(\mathrm{C}\left(\mathrm{R}_{3} \mathrm{I}\right.\right.$ I $\left.\left.\mathrm{R}_{2}\right)+2 \mathrm{R}_{4}\right)$

Phase noise is the noise skirts that surround the carrier of any signal source. Due to amplitude limiting in oscillators, FSK is the dominant cause of phase noise. Phase noise is measured in $\mathrm{dBc} / \mathrm{Hz}$.

PSK modulator: In Phase-Shift Keying (PSK), the phase of a transmitted signal is varied to convey information. The state of each bit is determined according to the state of the preceding bit. If the phase of the wave does not change, then the signal state stays the same ( 0 or 1$)$. If the phase of the wave changes by $180^{\circ}$, that is if the phase reverses, then the signal state changes (from 0-1, or from 1-0). In Fig. 8, static logic is used to design the PSK modulator. Since the PSK modulators are bandwidth efficient, they are power hungry modulators.

Figure 9 shows the output of the PSK modulator. Depending upon the data transition, signal state changes from 1-0 or from 0-1.

Power amplifier: The schematic of a quasi complementary Class $\mathrm{AB}$ power amplifier which operates in class AB is shown in Fig. 10. Since PMOS transistors have limited current carrying capability, the complementary output stage is suitable only for delivering load power of the order of few hundred $\mathrm{m}$ watts or less. A composite transistor is a combination of PMOS and an NMOS transistor. This arrangement is called as quasi complementary output stage ${ }^{[13]}$. 


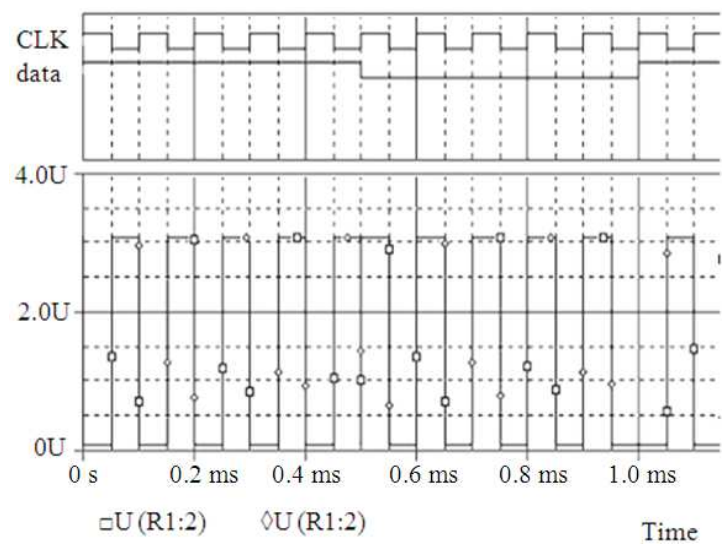

Fig. 9: Output of PSK modulator

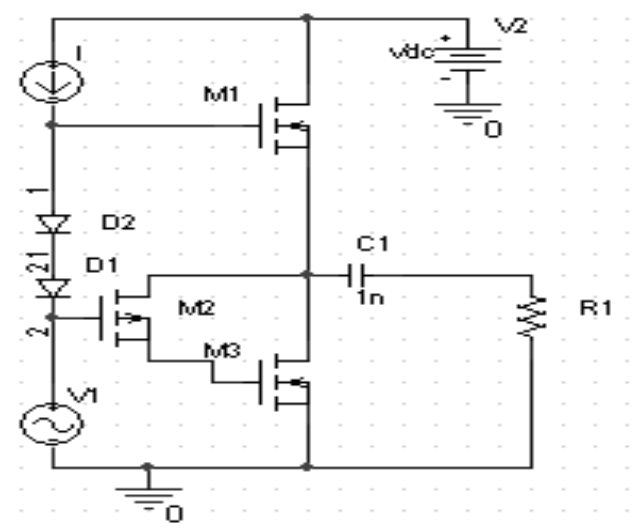

Fig. 10: Quasi complementary class AB power amplifier

It consumes a power of $0.2 \mathrm{~m}$ watts at $2.4 \mathrm{GHz}$ frequency. Usually power amplifier consumes much power when compared to other analog circuits.

\section{RESULTS}

In a typical sensor network, the transmitter sends out sporadic bursts of short data packets to neighboring sensor nodes $(<10 \mathrm{~m})$. The transmitter must exhibit fast response time and high efficiency ${ }^{[6]}$. The power dissipation in CMOS transmitter circuits consists of dynamic and static components. The dynamic power is proportional to $\mathrm{V}_{\mathrm{dd}}{ }^{2}$ and static power is proportional to $\mathrm{V}_{\mathrm{dd}}$, lowering the supply voltage is one of the most effective ways to reduce power dissipation in CMOS circuits.

From the golden equation ${ }^{[14]} \mathrm{P}=\mathrm{C}_{\mathrm{L}} \mathrm{V}^{2} \mathrm{f}$, if the operating frequency and the supply voltage is reduced,
Table 1: Simulated performance of the frequency synthesizer, ASK, FSK and PSK Transmitters at $27^{\circ} \mathrm{C}$

\begin{tabular}{ll}
\hline Vdd & $1.2 \mathrm{~V}$ \\
\hline Frequency synthesizer: & $120 \mathrm{~nm} \mathrm{CMOS}$ \\
Technology & $14.438 \mu \mathrm{w}$ \\
$\begin{array}{l}\text { Power consumed by the phase detector } \\
\text { with loop filter }\end{array}$ & $0.322 \mu \mathrm{w}$ \\
$\begin{array}{l}\text { Power consumed by the VCO } \\
\text { Power consumed by the frequency divider }\end{array}$ & $4.283 \mu \mathrm{w}$ \\
Total power consumed by the frequency & $19.043 \mu \mathrm{w}$ \\
synthesizer & \\
Tuning range of the synthesizer & $10 \mathrm{MHz}-2.4 \mathrm{GHz}$ \\
ASK transmitter: & $120 \mathrm{~nm} \mathrm{CMOS}$ \\
Technology & $200.104 \mu \mathrm{w}$ \\
Power consumed by the ASK modulator & $200 \mu \mathrm{w}$ \\
Power consumed by the power amplifier & $400.104 \mu \mathrm{w}$ \\
Total power dissipation of the ASK & $-110 \mathrm{dBc} / \mathrm{Hz}$ \\
transmitter at $2.4 \mathrm{GHz}$ & \\
Phase noise & $120 \mathrm{~nm} \mathrm{CMOS}$ \\
FSK transmitter: & $320 \mu \mathrm{w}$ \\
Technology & $200 \mu \mathrm{w}$ \\
Power consumed by the FSK modulator & $520 \mu \mathrm{w}$ \\
Power consumed by the power amplifier & \\
Total power dissipation of the FSK & $-114 \mathrm{dBc} / \mathrm{Hz}$ \\
transmitter at $2.4 \mathrm{GHz}$ & \\
Phase noise & $120 \mathrm{~nm} \mathrm{CMOS}$ \\
PSK transmitter: & $5 \mathrm{mw}$ \\
Technology & $200 \mu \mathrm{w}$ \\
Power consumed by the PSK modulator & $5.2 \mathrm{mw}$ \\
Power consumed by the power Amplifier & \\
Total power dissipation of the PSK & $-103 \mathrm{dBc} / \mathrm{Hz}$ \\
transmitter at $2.4 \mathrm{GHz}$ & \\
Phase noise &
\end{tabular}

the power dissipation can be reduced much. The ASK/FSK/PSK transmitters designed here is implemented in $120 \mathrm{~nm}$ CMOS technology. The simulation results are presented using the circuit simulator ORCAD 9.2. A summary of results are tabulated in Table 1.

Table 2 shows the performance comparison of the various designs reported in the recent literature.

\section{DISCUSSION}

For this study the normalized energies at $1.2 \mathrm{~V}$ are considered for simulation and are extrapolated over a range of $\mathrm{V}_{\mathrm{DD}}$ using simulation model. The frequency synthesizer consumes $19.043 \mu \mathrm{w}$ power. The ASK, FSK and PSK transmitters consume 400.104, $520 \mu \mathrm{w}$ and $5.2 \mathrm{mw}$ respectively at $2.4 \mathrm{GHz}$ frequency. When compared to the previous results the three transmitters designed here provide better phase noise performance. The surface area of the ASK transmitter is $41.7 \mu \mathrm{m} 2$ and for the FSK, it is $58.3 \mu \mathrm{m}^{2}$. The PSK transmitter occupies more area of $265.3 \mu \mathrm{m}^{2}$ when compared to the other two transmitters. The Layout of the transmitters are shown in Fig. 11a-c. For Wireless sensor nodes, 
Table 2: Performance comparison of the transmitters available in the literature

\begin{tabular}{|c|c|c|c|c|c|c|c|c|c|c|}
\hline \multirow{2}{*}{$\begin{array}{l}--- \\
\text { Ref }\end{array}$} & \multirow[b]{2}{*}{ [3] } & \multirow[b]{2}{*}{ [5] } & \multirow[b]{2}{*}{ [6] } & \multirow[b]{2}{*}{ [9] } & \multirow[b]{2}{*}{ [12] } & \multirow[b]{2}{*}{ [13] } & \multirow[b]{2}{*}{ [15] } & \multicolumn{3}{|c|}{ This work } \\
\hline & & & & & & & & ASK & FSK & PSK \\
\hline$\overline{\text { Vdd }}$ & -- & 2.3 & 1.8 & - & $1.2 \mathrm{~V}$ & $2.5 \mathrm{~V}$ & $2.6 \mathrm{~V}$ & $1.2 \mathrm{~V}$ & $1.2 \mathrm{~V}$ & $1.2 \mathrm{~V}$ \\
\hline \multirow[t]{2}{*}{ Tech } & $0.18 \mathrm{um}$ & $0.25 \mathrm{um}$ & $0.18 \mathrm{um}$ & $0.5 \mathrm{um}$ & $0.12 \mathrm{um}$ & $0.35 \mathrm{um}$ & $0.35 \mathrm{um}$ & $0.12 \mathrm{um}$ & $0.12 \mathrm{um}$ & $0.12 \mathrm{um}$ \\
\hline & CMOS & CMOS & CMOS & CMOS & CMOS & Bi CMOS & CMOS & CMOS & CMOS & CMOS \\
\hline fVCO [MHz] & 540 & $6.5 \mathrm{GHz}$ & $2.4-2.5 \mathrm{GHz}$ & 900 & $2.4 \mathrm{GHz}$ & 900 & 900 & $2.4 \mathrm{GHz}$ & $2.4 \mathrm{GHz}$ & $2.4 \mathrm{GHz}$ \\
\hline $\begin{array}{l}\text { Phase noise } \\
{[\mathrm{dBc} / \mathrm{Hz}] @ 10 \mathrm{kHz}}\end{array}$ & -104 & -112 & -93 & -92 & -110 & -82 & -88 & -110 & -114 & -103 \\
\hline Power [mw] & 4.9 & $22 \mathrm{mw}$ & $8 \mathrm{mw}$ & 29 & $0.392 \mathrm{mw}$ & 17 & 18 & 0.4 & 0.52 & $5.2 \mathrm{mw}$ \\
\hline Etc & w/o DSM & - & - & w/o VCO & with VCO & w/o VCO & - & - & - & - \\
\hline
\end{tabular}

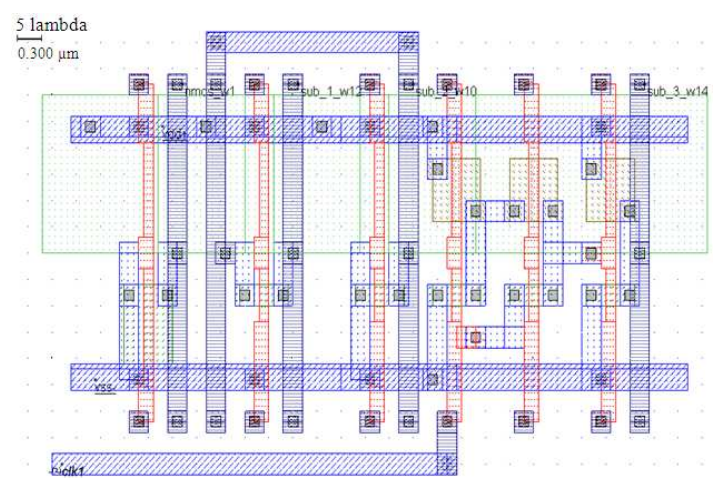

Fig. 11a: Layout of the ASK transmitter

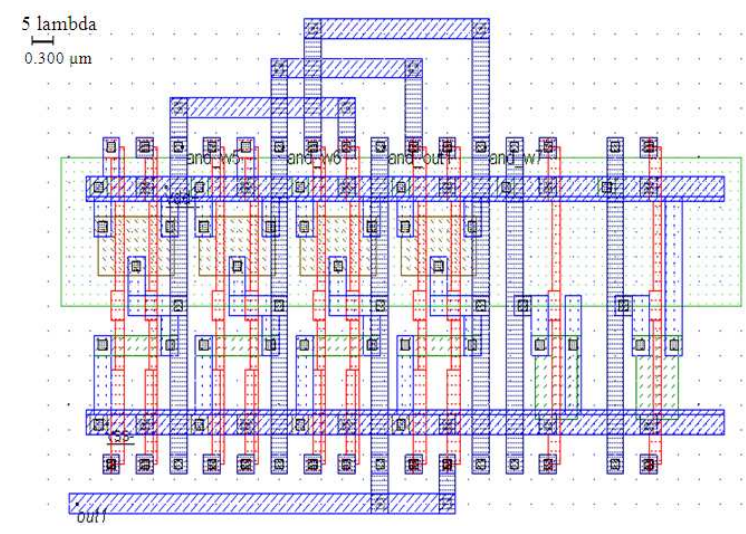

Fig. 11b: Layout of the FSK Transmitter

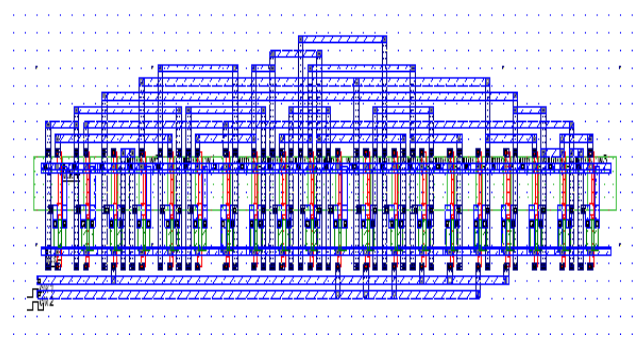

Fig. 11c: Layout of the PSK Transmitter in order to accommodate large amount of circuitry in a small chip the dimension of the devices should be made smaller.

\section{CONCLUSION}

The ASK/FSK/PSK transmitters were implemented in $120 \mathrm{~nm}$ CMOS technology. The ASK transmitter consumed $400.104 \mu \mathrm{w}$ power from $1.2 \mathrm{~V}$ supply at 2.4 $\mathrm{GHz}$ frequency. The sensor nodes using ASK transmitters are suitable for noisy environmental conditions. The FSK transmitter consumed $520 \mu \mathrm{w}$ power at the same frequency. These are suitable for long range WSN applications. The PSK transmitter consumed $5.2 \mathrm{mw}$ at $2.4 \mathrm{GHz}$. Since PSK transmitters are BW efficient, power consumption is more when compared to the other type of transmitters. For such applications PSK transmitters are suitable. The transmitters can also be implemented using the advanced CMOS technologies at the expense of short channel effects such as velocity saturation, mobility degradation and drain-induced barrier-lowering.

\section{REFERENCES}

1. Ammer and J. Rabaey, 2005. Low power synchronisation for wireless sensor network MODEMs. Proceedings of the IEEE Wireless Communications and Networking Conference, Mar. 13-17, New Orleans, Louisiana, USA., pp: 670675. DOI: $10.1109 /$ WCNC.2005.1424588

2. Karl, H. and A. Willig, 2005. Protocols and Architectures for Wireless Sensor Networks. The Atrium, Southern Gate, John Wiley and Sons Ltd, Chichester, West Sassex PO19 8SQ, England, ISBN: 0470095105, pp: 497.

3. Choi, H., S. Shin, Y. Ku, M, Jeong and K. Lee, 2003. A $4.9 \mathrm{~mW} 270 \mathrm{MHz}$ CMOS frequency Synthesizer/FSK modulator. Proceeding of the IEEE Symposium on Radio Frequency Integrated Circuits, June 8-10, IEEE Xplore Press, USA., pp: 443-446. $\mathrm{http}$ ://ieeexplore.ieee.org/xpl/freeabs_all.jsp?tp=\& arnumber $=1213981 \&$ isnumber $=27289$ 
4. Melly, T. et al., 2001. An ultra low power uhf transceiver integrated in a standard digital cmos process transmitter. IEEE J. Solid State Circ., 36: 467-472. DOI: $10.1109 / 4.910485$

5. Cho, S.H. et al., 2002. A $6.5 \mathrm{GHz}$ CMOS FSK modulator for wireless sensor applications. Proceeding of the Symposium on Circuits Digest of Technical Papers, (VISL'02), IEEE Xplore Press, USA., pp: 182-185.

DOI : 10.1109/VLSIC.2002.1015079

6. Dan Lei Yan Hui Teo et al., 2006. A low-power FSK modulator using fractional-N synthesizer for wireless sensor network application. Proceedings of the IEEE Symposium on Radio Frequency Integrated Circuits (RFIC), June 11-13, San Francisco, CA., pp: 184-187.

DOI: 10.1109/RFIC.2006.1651121

7. Shuguang, H. et al., 2006. A 8.0-mw 1-mbps ask transmitter for wireless capsule endoscope applications. Proceedings of the IEEE Symposium on Radio Frequency Integrated Circuits, June 1113, San Francisco, CA., pp: 252-255.

DOI: $10.1109 /$ Rfic. 2006.1651138

8. Pierret, R.F., 1996. Semiconductor device fundamentals. 2nd Edn., Addison-Wesley, Reading, MA., pp: 792.

9. Rhee, W., B. Song and A. Ali, 2000. A 1.1-GHz CMOS fractional-N frequency synthesizer with a 3b third-order $\Delta \Sigma$-modulator. IEEE J. Solid-State Circ., 35: 1453-1460.

DOI: 10.1109/ ISSCC.2000.839747
10. Roy, K. and S.C. Prasad, 2000. Low Power CMOS VLSI Circuit Design. 1nd Edn., Wiley, New York, ISBN: 10: 047111488X, pp: 376.

11. Yeap, G.K., 1998. Practical Low Power Digital VLSI Design. Kindle Edn., Kluwer Academic Publishers, Norwell, MA., ISBN: 0792380096, pp: 233.

12. Sasilatha, T. and J. Raja, 2007. Design and analysis of a $1.2 \mathrm{~V}, 2.4 \mathrm{GHz}$ low power ASK transmitter for wireless micro sensor nodes. Proceedings of the IEEE Conference on Wireless Communication and Sensor Networks, Dec. 13-15, Allahabad, pp: 1720. DOI: 10.1109/WCSN.2007.4475739

13. Rashid, M.H., 1999. Micro Electronic Circuits, Analysis and Design. PWS Publishing Compny, USA., ISBN:981-4040-30-4, pp: 990.

14. Hegazi, E. and A.A. Abidi, 2002. A $17 \mathrm{~mW}$ transmitter and frequency synthesizer for $900 \mathrm{MHz}$ GSM fully integrated in 0.35 um CMOS. Proceeding of the Symposium on Circuits Digest of Technical Papers, (VLSI'02), IEEE Xplore Press, USA., pp: 234-237.

DOI: $10.1109 /$ VLSIC.2002.1015026

15. Rhee, W., B. Song and A. Ali, 2002. An 18-mW 2.5-GHz/900-MHz BiCMOS dual frequency synthesizer with $<10-\mathrm{Hz}$ RF carrier resolution. IEEE J. Solid-State Circ., 37: 515-520.

DOI: $10.1109 / 4.991389$ 